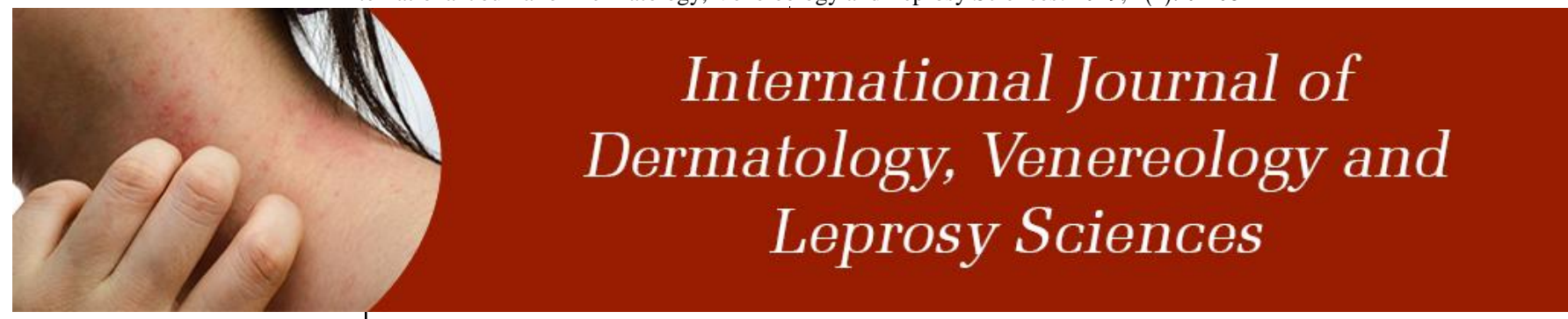

E-ISSN: 2664-942X P-ISSN: 2664-9411 Derma 2019; 2(1): 01-03 Received: 03-11-2018 Accepted: 05-12-2018

Dr. Alexander Smith Department of Dermatology, European Academy of Dermatology and Venereology, Lugano, Switzerland
Correspondence

Dr. Alexander Smith

Department of Dermatology,

European Academy of

Dermatology and Venereology,

Lugano, Switzerland

\section{Assessment of cases of Herpes zoster- A clinical study}

\section{Dr. Alexander Smith}

DOI: https://doi.org/10.33545/26649411.2019.v2.i1a.15

\begin{abstract}
Background: Herpes zoster caused by the neurodermotropic virus called "varicella zoster virus" is distributed worldwide. The present study was conducted to assess cases of Herpes zoster.

Materials \& Methods: The present study was conducted on 75 cases of Herpes Zoster reported to the department. The segment of involvement, morphology, and pattern of the lesions, regional lymph node enlargement, motor complications, dissemination of the lesions etc. were recorded in all patients.

Results: Out of 75 patients, males were 45 and females were 30. Age group 0-10 years had 2 patients, 11-20 had 4, 21-30 had 10, 31-40 had 16, 41-50 had 18, 51-60 had 20 and >60 years had 5 patients. The difference was significant $(P<0.05)$. There was involvement of cranial nerve in 30 , cervical in 8 , thoracic in 15 , lumber in 6 , sacral in 10 , cervico- thoracic in 4 and thoraco- lumber in 2 cases. The difference was significant $(P<0.05)$.

Conclusion: Authors found that common age group involved was 41-50 years and cranial nerve was mostly affected.
\end{abstract}

Keywords: Cervico- thoracic, Herpes zoster, Varicella zoster

\section{Introduction}

Herpes zoster caused by the neurodermotropic virus called "varicella zoster virus" is distributed worldwide. This benign localized viral disease has been recognized as a distinct entity since ancient times. It manifests as a result of reactivation of the virus laid dormant in the sensory ganglion following a clinical or sub clinical varicella (chicken pox) infection early in life or occasionally in utero ${ }^{[1]}$.

Replication and transmission of the virus in the nerves and skin lead to the cardinal features of herpes zoster-pain and rash. In some people the rash is preceded by a prodromal phase lasting 48-72 hours or longer, consisting of throbbing pain and paraesthesia in the region of the affected sensory nerve ${ }^{[2]}$. This may sometimes be confused with other acute medical conditions such as angina, cholecystitis, or renal colic, depending on the dermatome involved. The rash of herpes zoster is typically vesicular, affects a single dermatome, and lasts for three to five days before the lesions pustulate and scab ${ }^{[3]}$

Complications due to the involvement of ophthalmic, splanchnic, cerebral, and motor nerves are reported in herpes zoster. However, the most commonly seen complication is post-herpetic neuralgia ${ }^{[4]}$. Vaccination against herpes zoster virus is the mainstay of prevention of herpes zoster infection. Many treatment modalities have been developed for herpes zoster infection as well as for post-herpetic neuralgia. Nevertheless, approximately $22 \%$ of patients with herpes zoster still suffer from post- herpetic neuralgia ${ }^{[5]}$. Rise in the incidence of herpes zoster and post-herpetic neuralgia is expected with the increase in life expectancy and increase in prevalence of the modern-day epidemic human immunodeficiency virus (HIV). Wider use of varicella vaccination leads to reduced prevalence of varicella, thereby resulting in reduced chances of periodic re-exposure to varicella. This in turn can reduce natural boosting of immunity and lead to an increased incidence of herpes zoster ${ }^{[6]}$. The present study was conducted to assess cases of Herpes zoster.

\section{Materials \& Methods}

The present study was conducted in the department of Dermatology. It comprised of 75 cases of Herpes Zoster reported to the department. The study was approved from the institutional 
ethical committee. All were informed regarding the study and written consent was obtained. Data such as name, age, gender etc. was record. The segment of involvement, morphology, and pattern of the lesions, regional lymph node enlargement, motor complications, dissemination of the lesions etc. were recorded in all patients. Results were subjected to statistical analysis. $\mathrm{P}$ value less than 0.05 was considered significant.

\section{Results}

Table 1: Distribution of patients

\begin{tabular}{|c|c|c|}
\hline Gender & Males & Females \\
\hline Number & 45 & 30 \\
\hline
\end{tabular}

Table I shows that out of 75 patients, males were 45 and females were 30 .

Table 2: Age wise distribution of cases

\begin{tabular}{|c|c|c|}
\hline Age group (Years) & Number & P value \\
\hline $0-10$ & 2 & \\
\hline $11-20$ & 4 & \multirow{2}{*}{0.01} \\
\hline $21-30$ & 10 & \\
\hline $31-40$ & 16 & \\
\hline $41-50$ & 18 & \\
\hline $51-60$ & 20 & \\
\hline$>60$ & 5 & \\
\hline
\end{tabular}

Table II, shows that age group 0-10 years had 2 patients, 11 20 had 4, 21-30 had 10, 31-40 had 16, 41-50 had 18, 51-60 had 20 and $>60$ years had 5 patients. The difference was significant $(P<0.05)$.

Graph I: Segmental distribution of zoster

\begin{tabular}{|c|c|c|}
\hline Region & Number & \multirow{2}{*}{ P value } \\
\hline Cranial & 30 & \multirow{2}{*}{0.01} \\
\hline Cervical & 8 & \\
\hline Thoracic & 15 & \\
\hline Lumber & 6 & \\
\hline Sacral & 10 & \\
\hline Cervico-thoracic & 4 & \\
\hline Throaco- lumbar & 2 & \\
\hline
\end{tabular}

Table III, graph II shows that there was involvement of cranial nerve in 30 , cervical in 8 , thoracic in 15 , lumber in 6 , sacral in 10, cervico- thoracic in 4 and thoraco- lumber in 2 cases. The difference was significant $(P<0.05)$.

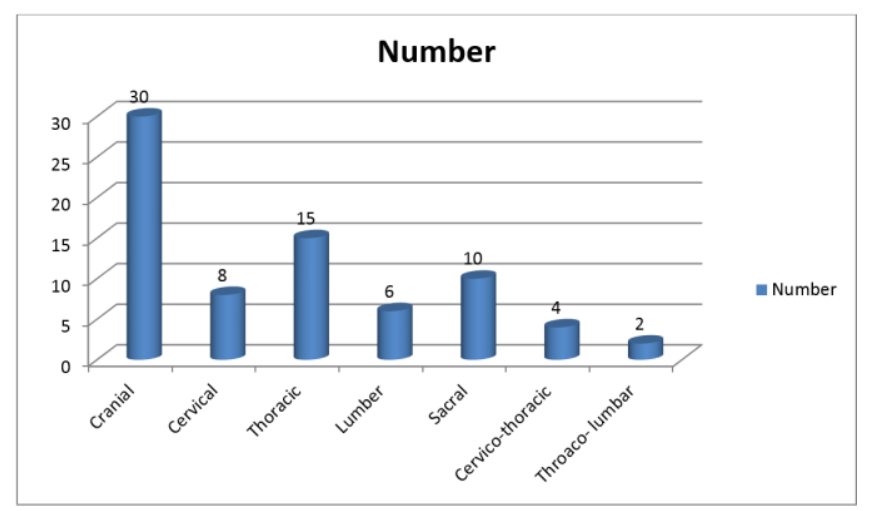

Graph II: Segmental distribution of zoster

\section{Discussion}

Herpes zoster is a clinical manifestation of the reactivation of latent varicella zoster virus infection ${ }^{[7]}$. It is a cause of considerable morbidity, especially in elderly patients, and can be fatal in immunosuppressed or critically ill patients. The pain associated with herpes zoster can be debilitating, with a serious impact on quality of life, and the economic costs of managing the disease represent an important burden on both health services and society ${ }^{[8]}$.

Herpes zoster, or shingles, is the painful eruption of a rash, usually unilateral, caused by the varicella zoster virus. Varicella zoster virus usually persists asymptomatically in the dorsal root ganglia of anyone who has had chickenpox, reactivating from its dormant state in about $25 \%$ of people to travel along the sensory nerve fibres and cause vesicular lesions in the dermatome supplied by that nerve. Herpes zoster is more common in people with diminished cell mediated immunity. This includes elderly people, patients with lymphoma, those receiving chemotherapy or steroids, and people with HIV. In contrast to herpes simplex, precise triggers for herpes zoster are not known ${ }^{[9]}$. The present study was conducted to assess cases of Herpes zoster.

In this study, out of 75 patients, males were 45 and females were 30 . We found that age group 0-10 years had 2 patients, 11-20 had 4, 21-30 had 10, 31-40 had 16, 41-50 had 18, 5160 had 20 and >60 years had 5 patients. Abdul et al. ${ }^{[10]}$. analyzed the incidence, pattern of occurrence and evolution of herpes zoster with special attention to provocative factors. Incidence of herpes zoster was mainly in the fourth and third decades of life. A definite history of chicken pox was present in only $63.4 \%$ cases. In the majority $(70 \%)$ herpes zoster occurred spontaneously. In $30 \%$ cases, immuno-suppression due to chemotherapy, malignancy, HIV infection, diabetes mellitus were observed. The commonest segment affected was thoracic $(42.4 \%)$ followed by cranial $(28.2 \%)$ and cervical $(12.1 \%)$. Majority resolved in 7-14 days except immunosuppressed. $34.6 \%$ of the patients had complications such as secondary bacterial infection, post herpetic neuralgia, and motor weakness. Ten patients had HIV infection as a provocative factor.

We observed that there was involvement of cranial nerve in 30 , cervical in 8 , thoracic in 15 , lumber in 6 , sacral in 10 , cervico- thoracic in 4 and thoraco- lumber in 2 cases. Gauthier et al. ${ }^{[11]}$ reported that $19.5 \%$ of herpes zoster patients develop PHN1 (pain persisting at least 1 month after rash onset) and $13.7 \%$ develop PHN3 (pain persisting at least 3 months after rash onset). Similarly, an Italian study showed a proportion of $9.4 \%$ for PHN1 and $7.2 \%$ for PHN3 among immuno-competent patients with herpes zoster.

Herpes zoster can usually be diagnosed clinically. However, early zoster and zoster presenting in the sacral and cervical area may be difficult to distinguish from herpes simplex. In these cases, the diagnosis can be confirmed by sending swabs to the local virology laboratory, but treatment should not be delayed while waiting for test results. The top of the lesion should be lifted and a sterile swab used to rub the base of the lesion. The swab should then be wiped across a sterile glass side or over three wells on a Teflon coated slide. The slide should be air dried and sent to the laboratory for staining with immunofluorescent antibodies ${ }^{[12]}$. 


\section{Conclusion}

Authors found that common age group involved was 41-50 years and cranial nerve was mostly affected.

\section{References}

1. Watson PN, Evens RJ. Post herpetic neuralgia: A review. Arch Neural 1986; 43:836-40.

2. Happenjans WB, Bibler MR, Orme RL. Prolonged cutaneous herpes zoster in acquired immunodeficiency syndrome. Arch Dermatol 1988; 126:1048.

3. Reusser P. Herpesvirus resistance to antiviral drugs: A review of the mechanisms, clinical importance and therapeutic options. J Hosp Infect 1996; 33:235-48.

4. Bernhard P, Obel N. Chronic ulcerating acyclovir resistant varicella zoster lesions in an AIDS patient. Scand J Infect Dis 1996; 27:623-5.

5. Buchbinder SP, Katz MI, Hessol NA, Liu JY, O'Malley PM, Underwood R, et al . Herpes zoster and human immunodeficiency virus infection. J Infect Dis. 1992; 166:1153-6.

6. Thiers BH, Sahn EE. Varicella zoster virus infections. In: Samuel L, Moschella, Harry J, Hurley, editors. Dermatology. 3rd ed. Philadelphia: W.B. Saunders Company, 1992, 797-806.

7. Sehgal VN, Rege VL, Kharangate VN. The natural history of Herpes Zoster. Indian J Dermatol Venereol Leprol. 1976; 42:86-89.

8. Ananthanarayan R, Panicker J. Human Immunodeficiency virus infection- AIDS. In: Ananthanarayan R, Panicker J, editors. Textbook of Microbiology. 5th ed. Hyderabad: Orient Longman Ltd, 1996, 538-52.

9. Chaudhary SD, Pahwa DA. A clinico-epidemiologic profile of herpes zoster in North India. Int J Dermatol Venereol Leprol. 1987; 53:213-6.

10. Abdul Latheef EN, Pavithran K. Herpes zoster: A clinical study in 205 patients. Indian J Dermatol. 2011; 56:529-32.

11. Pranesh N, Tandon VK, Kumar R. Herpes zoster: A clinical study. Indian J Dermatol Venereol Leprol. 1972; 38:152-5.

12. Jain C. Recurrent herpes zoster in a child with systemic lupus erythemtous. Indian J Dermatol Venereol Leprol. 1995; 61:38-9. 